\title{
Cost-Saving Preparation of Slips
}

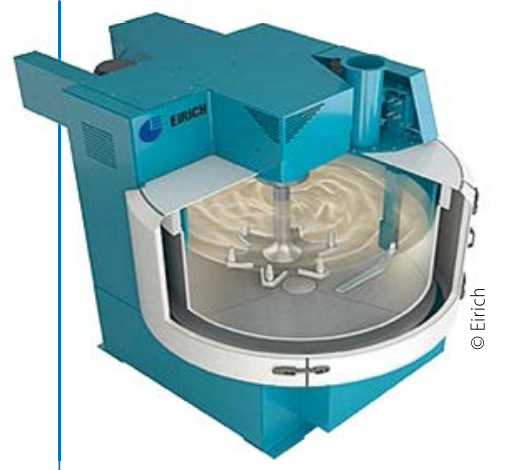

Energy costs are constantly rising. Eirich has set itself the goal of offering preparation methods to the ceramic industry that will enable users to save energy and produce more cost effectively. So that they can, in turn, gain an advantage in the international market. With Eirich's technology, preparation times can be drastically reduced, and energy savings of up to $50 \%$ can be achieved.

The main focus of the presentation is the cost-effective production of slips in the dispersing mixer, the so-called MixSolver. It will be of particular interest to manufacturers of sanitary ceramics. However, the MixSolver also offers advantages for the preparation of spray slip, e.g. for manufacturers of wall and floor tiles and of technical ceramics.

For sanitary ceramics, the quality of the slip plays a key role in slip casting or pressure filtration. Single and multi-stage processes are normally used for the preparation of slips made from clay and hard materials. Single-stage processes are operated with ball mills, while in multi-staged processes the clay-based raw materials are initially dissolved in stirring containers, and the hard materials are then added. Because the power input is low, both processes involve long process times. The use of a MixSolver offers significant advantages here.

Thanks to the unique operating principle of the Eirich mixer and its versatility in terms of potential applications, it is capable of processing all consistencies encountered in the ceramic industry, from powdery to viscoplastic or even liquid. It is also often possible to combine multiple preparation steps in a single unit. ceramitec: Hall B6,

Booth 201/302

\section{Kuraray}

\section{Ceramic Binder for Higher Green Strength}

In the production of technical ceramics, the binder plays a decisive role: It must ensure the appropriate viscosity of the liquid ceramic slip and exhibit a high green strength in the coldpressed mold. In addition, the binder should burn without residue during the firing process. Kuraray, a specialty chemicals company based in Hattersheim am Main, offers polyvinyl alcohol (PVOH) as a temporary ceramic binder with the Kuraray POVAL grades - including lowash variants.

Thanks to its special properties, POVAL is particularly suitable for technical ceramics. It is used in a number of areas within the ceramics industry, e.g. automotive, mechanical engineering and medical technology. It finds use in spark plugs, filters, electronic components and in computer chip capacitors. As Kuraray indicates POVAL has several ad- vantages in use, the required quantity is lower than with common binders and demonstrates very high green strength: The special ceramics retain their shape when not fired, even during shaking and transport between the processing steps. In the sintering process, the binder shows minimal shrinkage and decomposes at the end into water and carbon dioxide. In addition, the binder ensures a liquid ceramic slurry with very low viscosity, which makes processing more efficient. Due to this low viscosity significantly less water must be evaporated by firing. This considerably reduces the energy consumption.
Kuraray Europe in Hattersheim is a wholly owned subsidiary of the Kuraray Group, based in Tokyo (Japan), which has around 10,000 employees worldwide and a business volume of more than EUR 4 billion. Further information: www.kuraray.eu

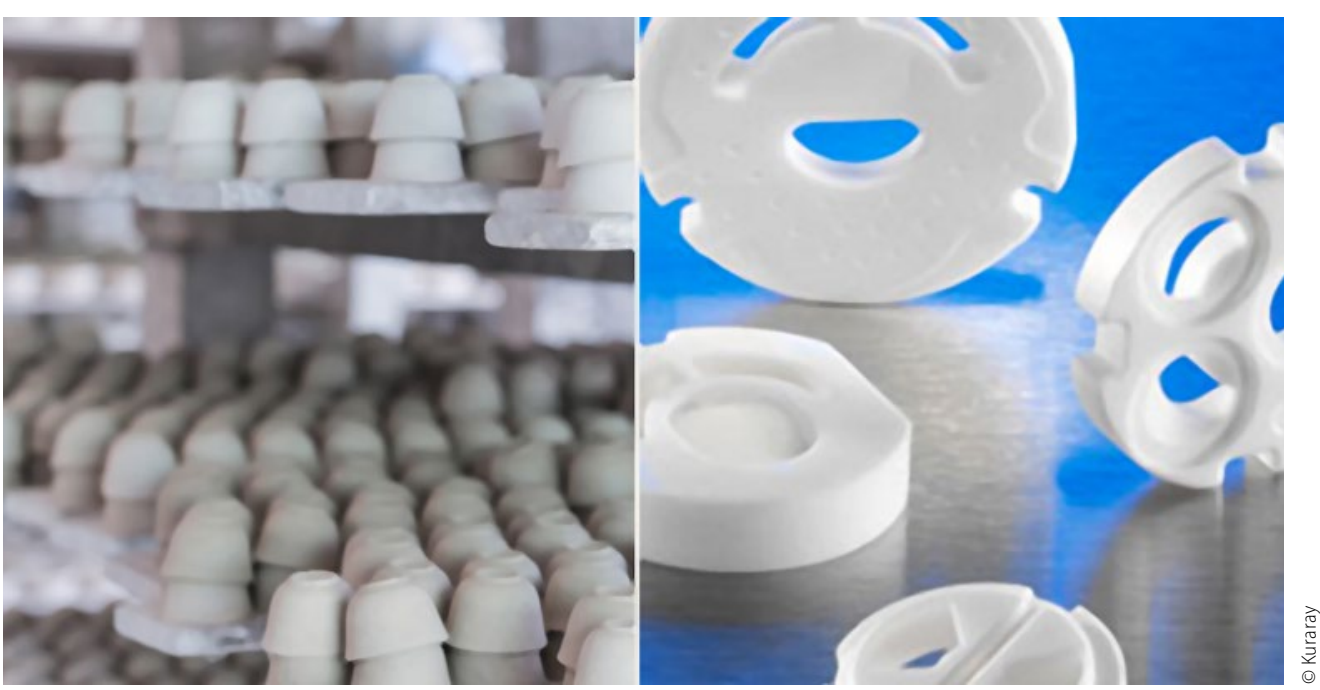

